$$
\text { "plaza" — 2005/2/17 — 18:41 — page } 423 \text { — \#1 }
$$

\title{
Proof without words: \\ Partial sum and sum of a geometric series
}

Ángel Plaza

Let $r$ be a positive real number such that $0<r<1$, then:

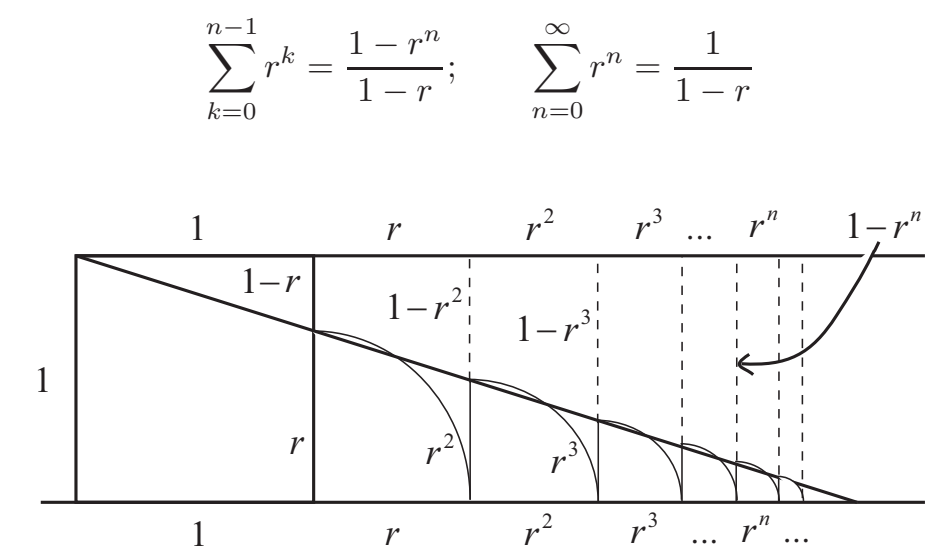

ÁNGEL PLAZA

DEPARTMENT OF MATHEMATICS

UNIVERSITY OF LAS PALMAS DE GRAN CANARIA

EDIFICIO DE INFORMÁTICA Y MATEMÁTICAS

35017-LAS PALMAS DE GRAN CANARIA

SPAIN

E-mail: aplaza@dmat.ulpgc.es

(Received November, 2004)

Copyright (c) 2004 by University of Debrecen 